\title{
Editorial
}

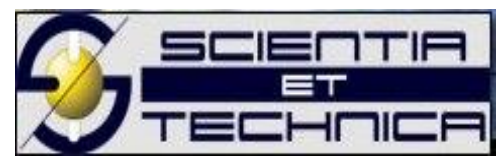

\section{Una Revisión General de los Artículos de Revisión}

A primera vista, escribir un artículo de revisión pareciera una tarea fácil de cumplir. Algunos académicos consideran desprevenidamente que es solo una lectura resumida de unos cuantos trabajos sobre un tema en particular, pero la tarea es algo más compleja.

Los artículos de revisión juegan un papel importante en las ciencias, ya que sintetizan de manera responsable algún aspecto desde el punto de vista bibliográfico entregando una visión general del estado del arte del tema tratado, sin realizar contribuciones originales. Por lo anterior, este tipo de trabajos tiene que ser realizado por expertos en el tema, los cuales deben reconocidos investigadores del área para entregar credibilidad a la audiencia. Usualmente, los artículos de revisión son escritos por estudiantes de doctorado, acompañados por sus tutores, durante los primeros años de su formación.

Al iniciarse una investigación doctoral se debe primero revisar la literatura científica existente, lo cual exigen mucho trabajo y esfuerzo. Primero, esta se realiza de manera general y luego se profundiza sobre un asunto puntual, el cual será una parte fundamental del trabajo investigativo que se desea proponer [1].

El artículo puede ser de dos categorias: narrativo o sistemático (existen otras categorias). Las revisiones narrativas están escritas en un formato fácil de leer y permiten discurrir el tema dentro de 
un más amplio rango. Las sistemáticas se centran en una particularidad dentro del tema de estudio.

Si bien las revisiones no son un aporte al estado del arte, este tipo artículos requieren el cumplimiento de algunos aspectos metodológicos insalvables, que brindan rigor y, por ende, validez al trabajo.

La revisión debe incluir de manera muy general, las siguientes partes:

La introducción: en esta se definen los objetivos de la investigación, destacando su relevancia en el área de estudio. Allí se puede indicar si el trabajo obedecerá a una revisión sistemática, o se realizará una indagación bibliográfica muy detallada y exhaustiva sobre un tema puntual [2]. Todo dependerá del objetivo. Esta parte, también podrá incluir una presentación general de artículo.

Metodología: se deben definir claramente, ya que esta brinda el soporte a las conclusiones de la revisión. Allí se puede indicar el protocolo de consulta, el cual puede desarrollarse presentado los campos seleccionados tales como fecha (ventana de revisión), palabras clave (de ser posible indicar el tesauro usado), tipo de fuentes (primarias, secundarias o terciarias), tipo de publicaciones (artículo indexado, artículo no indexado, memorias de eventos, libros, tesis doctorado, etc.), clave de registro (DOI, ISSN, ISBN etc.) asunto principal de trabajo y relevancia. Pueden darse muchos más campos de ser necesario. Si bien es posible considerar otros trabajos de revisión previos al que se realiza para recibir ideas, se debe ser cuidadoso porque estos pueden hacer "perezoso" al revisor y sesgar la relevancia los trabajos nuevos y anteriores encontrados. El aspecto cuantitativo de la metodología no debe tomarse a la ligera, ya que una revisión seria requiere la sintesis de cientos de trabajos (mínimo 50 para Scientia et Technica) para poder realizarse y considerarse una revisión rigurosa. En cada caso, se debe indicar el número de fuentes primarias (información original que ha sido publicada por primera vez), secundarias (localizadores fuentes primarias) o terciarias (colección de referencia de la biblioteca) usadas. En ningún caso se deben citar fuentes que no tengan trazabilidad como sitios tipo "wiki" o "blogs".

Desarrollo de la revisión: puede presentar el estado del arte en orden cronológico o secuencial por tema. En todo el caso se debe realizar citaciones de manera adecuada para cada trabajo referido con el máximo rigor.

Resultados y Discusión: deben mostrar los hallazgos más relevantes que aporten a dar respuesta al problema planteado en la introducción sin ser aún concluyentes. Pueden usarse tablas o figuras que resuman el trabajo. 
Conclusión: indica si el trabajo entregó evidencia suficiente para dar respuesta al problema planteado. Se debe ser honesto y expresar si fue suficiente o se debe seguir escudriñando sobre el tema. Aquí también, pueden evidenciarse las limitaciones encontradas en la revisión, lo que determinará el alcance del trabajo en términos de su usabilidad.

La UNESCO reconoce los trabajos recapitulativos como una fuente de información secundaria [3] válida. De igual forma, La revista Scientia et Technica se ha tomado en serio los artículos de revisión y reconoce su aporte. En virtud de esto, se exige que los trabajos cuenten con todo el rigor científico general expresado en esta editorial, la cual resume aspectos más generales. En cualquier caso, la carta de remisión, para su sometimiento, debe indicar claramente la relevancia y aporte de la revisión al presentarse, entregando un antecedente académico de los investigadores que la someten. De no ser así, no serán considerados para evaluación. Esto no exonera el paso por pares de artículos sometidos. Finalmente, la revista Scientia et Technica queda atenta a sus contribuciones las cuales sean caracterizado por su alta calidad.

\section{REFERENCES}

[1] M. Pautasso, "Ten Simple Rules for Writing a Literature Review", PLoS Computational Biology, vol. 9, no. 7, p. e1003149, 2013. Available: 10.1371/journal.pcbi.1003149.

[2] Ö. Gülpınar and A. çal Güçlü, "How to write a review article?", vol. 1, pp. 44-48, 2013. Available: 10.5152/tud.2013.054 [Accessed 22 March 2020].

[3] A. Martinsson, "Guía para la redacción de articulos científicos destinados a la publicación", Unesdoc.unesco.org, 2020. [Online]. Available: https://unesdoc.unesco.org/ark:/48223/pf0000055778_spa. [Accessed: 22- Mar- 2020].

\section{Autor}

\section{Jimmy Alexander Cortes Osorio iD}

Docente Titular Departamento de Física

Editor Jefe - Revista Scientia et Technica

Grupo Investigación Robótica Aplicada

Linea: Computer Vision and Machine Learning

Investigador Asociado Reconocido por Colciencias

Universidad Tecnológica de Pereira

Orcid: http:/ /orcid.org/0000-0002-0413-807X 